\title{
Study of thermal stability of (3-aminopropyl)trimethoxy silane-grafted titanate nanotubes for application as nanofillers in polymers
}

\author{
Milivoj Plodinec ${ }^{\mathrm{a}}$, Andreja Gajović ${ }^{\mathrm{a}^{*}}$, Damir Iveković ${ }^{\mathrm{b}}$, Nenad Tomašićc ${ }^{\mathrm{c}}$, Boris \\ Zimmerman $^{\mathrm{a} 2}$, Jelena Macan ${ }^{\mathrm{d}}$, Tatjana Haramina ${ }^{\mathrm{e}}$, D. S. Su ${ }^{\mathrm{f}}$, Marc Willinger ${ }^{\mathrm{f}}$,
}

${ }^{a}$ Division of Materials Physics, Ruđer Bošković Institute, Zagreb, Bijenička 54, HR10000 Zagreb, Croatia

a2 Division of Organic Chemistry and Biochemistry, Ruđer Bošković Institute, Zagreb, Bijenička 54, HR-10000 Zagreb, Croatia

${ }^{b}$ Laboratory for General and Inorganic Chemistry and Electroanalysis, Faculty of Food Technology and Biotechnology, University of Zagreb, Pierottijeva 6, HR-10000 Zagreb, Croatia

${ }^{c}$ Institute of Mineralogy and Petrography, Faculty of Science, University of Zagreb, Horvatovac 102, HR-10000 Zagreb, Croatia

${ }^{\mathrm{d}}$ Department of Physical Chemistry, Faculty of Chemical Engineering and Technology, University of Zagreb, Marulićev trg 19, HR-10000 Zagreb, Croatia

${ }^{\mathrm{e}}$ Department of Materials, Faculty of Mechanical Engineering and Naval Architecture, University of Zagreb, Ivana Lučića, HR-10002 Zagreb, Croatia ${ }^{\mathrm{f}}$ Fritz-Haber-Institute der Max-Planck-Gesellschaft, Faradayweg 4-6, 14195 Berlin, Germany

\footnotetext{
* Corresponding author: Phone: +385 1 4561106, Fax: +385 1 4680112, e-mail address: gajovic@,irb.hr (A. Gajović)

${ }^{\dagger}$ now at Insitute of Metal Researh, Chinese Academy of Science, 72 Wenhua Road, Shenyang, China
} 


\section{ABSTRACT}

Protonated titanate nanotubes (TiNT-H) were surface-modified with (3aminopropyl)trimethoxy silane (APTMS) by novel method suitable for syntheses of large amounts of materials with low costs. Usage of prepared nanotubes for polymer reinforcement was studied. Since the thermal stability of nanofiller was important to preserve their functional properties, stability was studied by in situ high temperature measurements. The most thermally stable nanotubes, silanized for $20 \mathrm{~min}$, were used for preparation of epoxy-based nanocomposites. The nanofiller formed smaller (few hundreds of $\mathrm{nm})$ and larger (few $\mu \mathrm{m})$ aggregates in polymer matrix, and the amount of aggregates increased with increasing nanofiller content. APTMS modified titanate nanotubes bonded well with the epoxy matrix since amine groups on the TiNTs surface can react with epoxy group to form covalent bonds between the matrix and the nanofiller. Very small addition $(0.19-1.52 \mathrm{wt} \%)$ of nanotubes significantly increased the glass transition temperature and the modulus in rubbery state of the epoxy based polymer. Smaller nanofiller content lead to larger increase in these parameters and therefore better dynamic mechanical properties due to the smaller amount of large aggregates. APTMS-modified titanate nanotubes were proven as promising nanofiller in epoxy based nanocomposites.

KEYWORDS: titanate nanotubes surface modified by (3-aminopropyl)trimethoxy silane; thermal stability; epoxy-based nanocomposites. 


\section{INTRODUCTION}

Titanate nanotubes (TiNT) [1] are a mesoporous $\mathrm{TiO}_{2}$-based nanomaterial extensively studied over the last decade. In comparison to other nanotubular materials, TiNT exhibit some distinct advantages, including the ease with which they can be prepared in high purity and high yield, a low cost, a high specific surface area, a high density of surface OH-groups, and ion-exchange and semiconducting properties [1]. Due to this favourable combination of properties, TiNT have a great potential for applications in catalysis, solar energy conversion, solid-state batteries, and reinforced composite materials [1]. The most straightforward way to synthesize TiNT is the reaction of $\mathrm{TiO}_{2}$ powder with concentrated aqueous $\mathrm{NaOH}$ solution at $110-160{ }^{\circ} \mathrm{C}$ [2]. TiNT synthesized in this way exhibit an extremely high aspect ratio: depending on the synthesis conditions, the inner and outer diameters of nanotubes typically range from 3 to $5 \mathrm{~nm}$, and 7 to $10 \mathrm{~nm}$, respectively, and their length varies from several hundred nanometers up to several micrometers. The walls of TiNT consist of several (typically 3-5) negatively charged concentric nanolayers composed of edge-sharing $\mathrm{TiO}_{6}$-octahedra [3-6]. The nanolayers are mutually spaced by $0.7 \mathrm{~nm}$ and the spaces between layers are occupied by hydrated charge-compensating cations (usually $\mathrm{Na}^{+}$or $\mathrm{H}_{3} \mathrm{O}^{+}$), which are mobile and can be readily exchanged $[6,7]$.

Due to the high density of surface $\mathrm{OH}$-groups (in average, $5.8 \mathrm{OH}$-groups per $\mathrm{nm}^{2}$ [8]), TiNT are a promising material for surface modifications, particularly with functionalized alkoxysilanes, $(\mathrm{RO})_{3} \mathrm{Si}^{-} \mathrm{R}^{\prime} \mathrm{X}$, where $\mathrm{R}^{\prime} \mathrm{X}$ denotes an alkyl chain terminating with a functional group $\mathrm{X}$. Depending on the nature of the group $\mathrm{X}$, the physical and chemical properties of the TiNT surface can be varied within a wide range and the potential field of application of TiNT can be greatly expanded. However, there are several factors 
that limit the technological applicability of TiNT, among which the most serious are the low resistance of TiNT towards strong mineral acids [9], instability of TiNT under the conditions of high mechanical stress $[10,11]$, and their thermal instability [12-14].

In many of technologically important applications, titanate nanotubes are exposed to chemically aggressive media, or physically demanding surroundings, which can affect their stability. It is therefore important to understand the range of operational conditions under which the nanotubes are stable, and the transformations of nanotubes which occur outside these conditions. A knowledge of the thermal stability of modified titanate nanotubes is of the main importance, since some applications or manipulations (such as: catalyst supports or the formation of composite films) require an increased operating temperature. At elevated temperatures there are at least three processes occurring with protonated titanate nanotubes, namely: dehydration, crystal structure transformation and a modification of the morphology. All three processes occur simultaneously, and each has a characteristic range of temperatures related to their particular phase transition.

Titanate nanotubes are a promising nanofiller for polymer composite materials. Their modulus is comparable to that of carbon nanotubes, they can be produced in large quantities, and the chemistry of their surface modification is the same as for conventional inorganic fillers $[15,16]$. Despite that, to our knowledge few examples of titanate nanotube/polymer composites have been published [17-20].

In this work, chemically modified TiNTs were studied. The aim was to prepare TiNT-H surface-modified with (3-aminopropyl)trimethoxy silane (APTMS) that can be further used for strengthening of polymers. Structural and morphological changes of TiNT during the modification process were studied, as well as the temperature stability of 
modified TiNT. The phase transformation from hydrogen titanate to the anatase $\mathrm{TiO}_{2}$ was observed during heating but without the collapse of the tubular morphology. In order to investigate their applicability as nanofillers, the modified TiNTs that had shown the highest temperature stability were used to prepare nanocomposite materials based on epoxy resin, since amine groups on the TiNTs surface can react with epoxy group to form covalent bonds between the matrix and the nanofiller. In order to determine chemical or physical modifications of the matrix by the introduction of TiNTs, thermomechanical properties of both the neat epoxy polymer and the nanocomposites were investigated.

\section{EXPERIMENTAL}

\subsection{Synthesis of APTMS-modified TiNT}

Titanate nanotubes in the protonated form (TiNT-H) were synthesized by reaction of $\mathrm{TiO}_{2}$ powder $(99.8 \%$ anatase, 325 mesh, Aldrich) with $30 \%(\mathrm{w} / \mathrm{w})$ aqueous $\mathrm{NaOH}$ solution at $130{ }^{\circ} \mathrm{C}$ for $20 \mathrm{~h}$, followed by an ion-exchange in $0.1 \mathrm{M} \mathrm{HCl}$, as described previously $[11,14,21]$. In order to graft (3-aminopropyl)trimethoxysilane (APTMS) molecules on the surface of TiNT, the mass of $0.25 \mathrm{~g}$ of TiNT-H was suspended in $25 \mathrm{~mL}$ of dry dichloromethane and $0.5 \mathrm{~mL}$ of APTMS (98\%, Aldrich) was added to the suspension. After the predetermined time (20, 45, 90, or $180 \mathrm{~min})$, APTMS - grafted TiNT were vacuum filtered, extensively washed with dry dichloromethane to remove the excess organosilane, and dried at $60{ }^{\circ} \mathrm{C}$ for three hours. APTMS-grafted TiNT samples were labelled as TiNT- $\mathrm{NH}_{2}-x$, where $x$ indicates the duration of the silanization step in minutes. 


\subsection{Preparation of polymer nanocomposites}

An epoxy resin, diglycidyl ether of bisphenol A (DGEBA, Epikote 828 EL, Shell Chemicals) with the epoxy equivalent weight of $190 \mathrm{~g} / \mathrm{mol}$, and poly(oxypropylene) diamine (Jeffamine D230, Huntsman Corporation) as a curing agent for epoxy resin were used. The diamine was added in stoichiometric amount of $30 \mathrm{phr}$ (parts per one hundred parts of resin). To prepare the nanocomposite, the most thermally stable functionalization, TiNT-NH ${ }_{2}-20$, was selected. DGEBA was compounded with $0.19,0.38,0.76$ and $1.52 \mathrm{wt} \%$ of selected TiNT-NH$H_{2}$ for 75 minutes at $80{ }^{\circ} \mathrm{C}$ in an oil bath. To ensure good dispersion of the nanofiller, the blend was additionally treated in a heated ultrasonic bath for 15 minutes. After cooling to RT, diamine was added and homogenised with the resin and nanofiller for 60 minutes, and the resulting mixture poured into a mould and left to cure at RT for a week. Neat crosslinked epoxy was prepared in the same manner, only without addition of the nanofiller, to exclude the influence of preparation conditions on final properties of the crosslinked samples. Both the neat epoxy polymer and the nanocomposite were then cut into samples for thermomechanical investigation (dimensions are given in Table 1.), and postcured at $120^{\circ} \mathrm{C}$ for 24 hours.

\subsection{Characterization of TiNT samples and polymer nanocomposites}

The amount of APTMS grafted on the nanotube surface was determined by spectrophotometric ninhydrin method developed for the determination of primary amino groups on APTMS-modified silica [22], by using APTMS as a standard. All analyses were performed in triplicate. 
Spectroscopic characterization of samples was performed by Raman and Fourier transform infrared (FT - IR) spectroscopy. Raman spectroscopy measurements were performed using a Horiba Jobin-Yvon T64000 system equipped with an argon ion laser Coherent, Innova 400 operating at $514.5 \mathrm{~nm}$ for excitation. Raman data were collected with multi-channel charge-coupled device detector. A laser power of $20 \mathrm{~mW}$ was focused on samples using a 50x long working distance objective. FT - IR spectra were recorded at a resolution of $4 \mathrm{~cm}^{-1}$ using cosine apodization on an ABB Bomem MB102 single-beam spectrometer, equipped with cesium iodide optics and deuterated triglycine sulphate detector. The transmission spectra were recorded by measuring potassium bromide sample pellets. A sample-free setup was used to obtain the spectral background. Structural changes induced by thermal treatment of APTMS-grafted samples were studied by in situ hightemperature Raman and FT - IR spectroscopy, performed by heating the samples in thermal micro-chamber placed in the sample compartment of the spectrometer. The samples were heated from room temperature (RT) to $250{ }^{\circ} \mathrm{C}$ (for FT - IR spectroscopy measurements) and $500{ }^{\circ} \mathrm{C}$ (for Raman spectroscopy measurements) with the heating rate of $10{ }^{\circ} \mathrm{C} / \mathrm{min}$ and the spectra were recorded in regular temperature intervals of $50{ }^{\circ} \mathrm{C}$. After reaching the predetermined temperature, the heating was stopped and the samples were thermostated at this temperature for $15 \mathrm{~min}$ before recording the spectra.

The X-ray diffraction (XRD) patterns of samples were obtained using a Philips PW 3040/60 X'Pert PRO powder diffractometer employing $\mathrm{CuK} \alpha$ radiation at $45 \mathrm{kV}$ and 40 $\mathrm{mA}$. The step size was $0.02^{\circ}$, with the measuring time of $10 \mathrm{~s}$ per step.

Transmission electron microscopy (TEM) and high resolution TEM (HR-TEM) of samples were performed using Philips $\mathrm{CM}_{200} \mathrm{LaB}_{6}$ and FEG transmission 
electron microscopes operated at $200 \mathrm{kV}$, respectively. Scanning electron microscopy (SEM) measurements were performed using a Hitachi S-4800 with a cold FEG (Field Emission Gun). Images were taken in STEM mode with HV $15 \mathrm{kV}$. For TEM measurements of unmodified and APTMS-modified TiNTs, the samples were first suspended in chloroform by sonication, then a small drop of the suspension was transfered onto the carbon-coated copper grid, and finally the grid was dried in air.. Polymer nanocomposites were prepared for the TEM and STEM observations by ultramicrotomy.

Dynamic mechanical analysis (DMA) of polymer nanocomposite samples was performed on TTDMA Triton Technology instrument, in a tensile mode. The distance between the jaws was $7.5 \mathrm{~mm}$, the heating rate $2{ }^{\circ} \mathrm{C} / \mathrm{min}$, the amplitude of force modulation was $0.015 \mu \mathrm{m}$ and the frequency $1 \mathrm{~Hz}$. Three samples of each material were tested with very good reproducibility.

\section{RESULTS AND DISCUSSION}

Four samples of APTMS-modified titanate nanotubes differing in the amount of grafted silane were prepared by varying the reaction time between the nanotubes and APTMS from 20 to $180 \mathrm{~min}$. Depending on the reaction time, the amount of APTMS grafted to the nanotube surface varied between 0.606 and $0.829 \mathrm{mmol}$ per gram of silanized nanotubes, as determined by analysis of surface-bonded APTMS (Table 2). The modification and the structural changes of titanate nanotubes surface modified with APTMS were studied in situ at high temperatures by two complementary experimental 
techniques, Raman spectroscopy and FT - IR spectroscopy. The change of the crystal structure and the morphology of the titanate nanotubes before and after thermal treatment were investigated by XRD and TEM techniques.

\subsection{Vibrational spectroscopy of titanate nanotubes modified by (3-aminopropyl)trimethoxy} silane

With the aim to verify the APMTS grafting on the surface of TiNT, the Raman spectra of the APTMS-grafted samples (TiNT-NH $2-x, x=20,45,90,180)$ were recorded at $\mathrm{RT}$ in the frequency range of $50-3100 \mathrm{~cm}^{-1}$ and compared with the Raman spectrum of the unmodified TiNT (sample TiNT-H). Since the RT Raman spectra of all grafted samples appeared similar, the comparison of the spectra before and after the APTMS grafting is shown only for the sample TiNT-NH2-180 (Fig. 1a). The Raman spectrum of the sample TiNT-H shows the bands at 195, 269, 452, 665 and $831 \mathrm{~cm}^{-1}$, which are characteristic for the protonated trititanate nanotubes [14] and indicates that the sample TiNT-H have the $\mathrm{H}_{2} \mathrm{Ti}_{3} \mathrm{O}_{7}$ structure. These bands were preserved in the sample TiNT-NH-180 , indicating that the grafting of APTMS molecules onto the surface of TiNT-H does not alter the crystal structure of nanotubes. In addition, the spectrum of the sample TiNT- $\mathrm{NH}_{2}-180$ shows multiple bands in the spectral range of $1000-3100 \mathrm{~cm}^{-1}$, which is characteristic for vibrations of organic groups. Therefore, these bands can be attributed to the vibrational modes of APTMS molecules grafted on the nanotube surface (Table 3.).

FT - IR spectra of the unmodified titanate nanotubes (sample TiNT-H) and APTMS modified titanate nanotubes (sample TiNT-NH $2-180$ ) are shown in Fig. 1(b). Two most prominent bands on the spectra of both samples are the broad band appearing in the 
frequency range of $2600-3700 \mathrm{~cm}^{-1}$, which can be assigned to the $\mathrm{O}-\mathrm{H}$ stretching vibrations of the surface $\mathrm{OH}$ groups and interlayer $\mathrm{H}_{2} \mathrm{O} / \mathrm{H}_{3} \mathrm{O}^{+}$molecules, and the strong band centered at $1623 \mathrm{~cm}^{-1}$, which can be attributed to the $\mathrm{H}-\mathrm{O}-\mathrm{H}$ bending vibration mode of water molecules. Silanized nanotubes show a marked band at $1510 \mathrm{~cm}^{-1}$, characteristic of $\mathrm{NH}_{3}{ }^{+}$symmetric bending deformation [27], and multiple weaker bands in the frequency

range $1450-1300 \mathrm{~cm}^{-1}$, which can be assigned to the $\mathrm{CH}_{2}$ vibration modes of aminopropyl segment $[23,25,26]$. Band centered at $1120 \mathrm{~cm}^{-1}$ is characteristic of the $\mathrm{Si}-\mathrm{O}-\mathrm{Si}$ network, while sharp band at $1032 \mathrm{~cm}^{-1}$ corresponds to the vibrations of shorter linear $\mathrm{Si}-\mathrm{O}-\mathrm{Si}$ chains $[23,25,26]$. The appearance of amine, methylene, and siloxane bands in FT - IR spectrum of TiNT-NH $2-180$ clearly indicates successful grafting of APTMS molecules on the surface of titanate nanotubes. Detailed assignation of the vibrational bands appearing in the FT-IR spectrum of the sample TiNT-NH ${ }_{2}-180$ is shown in Table 3.

\subsection{In situ high temperature vibrational spectroscopy}

In order to study the thermal stability of the APTMS-grafted TiNT samples, two complementary vibrational spectroscopy techniques, Raman and FT - IR spectroscopy were employed. Raman spectroscopy was used to study the temperature stability of hydrogen titanate nanotubes skeleton (Fig. 2) since the phonons formed due to the vibrations of crystal lattice can be readily observed in the low frequency region of the vibrational spectrum, where the Raman bands are strong and well-resolved. Thermal stability of the surface-bound APTMS layer was, in contrast, studied by FT - IR spectroscopy (Fig. 3) since the FT - IR spectra of APTMS-grafted samples are more rich in details, and the vibrational bands due to the vibration modes of the grafted APTMS molecules are stronger 
and better resolved than the vibrational bands of surface-bound APTMS molecules appearing on the corresponding Raman spectra.

Four samples, TiNT- $\mathrm{NH}_{2}-x, x=20,45,90$ and 180, were heated in cryo/thermo micro chamber from RT to $500{ }^{\circ} \mathrm{C}$ and investigated by micro-Raman spectroscopy. The structural phase transition of titanate nanotube skeleton was expected in this temperature range, as indicated by TG and DSC measurements (not shown), as well as by our earlier investigation [14].

Figures 2 (a) - (d) shows Raman spectra of all investigated samples recorded in situ at temperatures denoted above spectra. During the heating of the sample TiNT-NH $2-20$ (Fig. 2(a)) at temperature of $400{ }^{\circ} \mathrm{C}$ a phase transition to anatase phase was observed. This is manifested as the appearance of the band at about $156 \mathrm{~cm}^{-1}$, which is characteristic for the most intensive band of anatase. With further heating at temperature of $500{ }^{\circ} \mathrm{C}$, other bands characteristic for anatase phase at 186, 399, 497 and $639 \mathrm{~cm}^{-1}$ were observed. After cooling the sample to RT the beginning of the phase transition from anatase to rutile was observed, reflected in the occurrence of rutile band at $246 \mathrm{~cm}^{-1}$. During heating process, besides the expected bands of anatase, at temperature of $300{ }^{\circ} \mathrm{C}$ additional band at $120 \mathrm{~cm}^{-1}$ appeared, and could be assigned to the sodium trititanate [28]. This band observed at 120 $\mathrm{cm}^{-1}$ in situ at $300{ }^{\circ} \mathrm{C}$ usually appears at $104 \mathrm{~cm}^{-1}$ at $\mathrm{RT}$, but with increasing temperature this band is shifted to higher wavenumbers [28].

In the spectrum of the sample TiNT-NH${ }_{2}-45$ heated at $300{ }^{\circ} \mathrm{C}$ (Fig. 2 (b)) the phase transition to the anatase phase was observed, as anatase bands at approximately 150, 192, 397,510 and $635 \mathrm{~cm}^{-1}$ were perceived. Similarly, band at 127 which could be assigned to 
the sodium trititanate [28] was observed. After cooling to the RT, bands of rutile at 240 and $431 \mathrm{~cm}^{-1}$ were observed.

In the remaining two samples TiNT-NH -90 and TiNT-NH -180 (Figs. 2 (c) and 2 (d)) similar behaviour as in the sample with the silanization time of 45 minutes were observed. Occurrence of the same anatase bands as in the first two samples was observed at $300{ }^{\circ} \mathrm{C}$, specifically at $152,195,392,507$ and $644 \mathrm{~cm}^{-1}$. In sample TiNT-NH ${ }_{2}-180$ phase transition has already started at temperatures above $200{ }^{\circ} \mathrm{C}$.

Comparing the Raman spectra of all samples, it is apparent that the most temperature stable sample is the one with the shortest time of silanization, TiNT-NH-20 . In this sample the phase transition to anatase has started at temperature of $400{ }^{\circ} \mathrm{C}$, while in other samples the transition started at temperatures of $300{ }^{\circ} \mathrm{C}$ or lower. This temperature of $400{ }^{\circ} \mathrm{C}$ is considerably higher than $175^{\circ} \mathrm{C}$ found in earlier work for the phase transition from TiNT-H form of nanotubes to the anatase phase [14].

In order to study the thermal stability of grafted APTMS, the sample TiNT- $\mathrm{NH}_{2}$ 180 was subjected to heating from RT to $250{ }^{\circ} \mathrm{C}$ and FT - IR spectra were recorded simultaneously at regular temperature intervals (Fig. 3). The most marked changes in the FT - IR spectra observed during the heating of the sample are the almost complete disappearance of the band centered at $3395 \mathrm{~cm}^{-1}$ and the great reduction in the intensity of the band at $1623 \mathrm{~cm}^{-1}$. These spectral changes indicate that the APTMS-grafted titanate nanotubes lose a substantial amount of water when heated to $250{ }^{\circ} \mathrm{C}$. Since the dehydration of titanate nanotubes precedes their phase transformation to anatase, the observed behavior of the sample TiNT- $\mathrm{NH}_{2}-180$ is in accordance with the conclusions on the thermal stability of the silanized TiNT samples drawn from the in situ heating Raman spectroscopy 
experiments, which demonstrated that the phase transition of TiNT- $\mathrm{NH}_{2}-x$ samples occur in the temperature range from 200 to $400{ }^{\circ} \mathrm{C}$. Except a slight broadening at higher temperatures, the bands related to the vibrational modes of the APTMS molecules grafted to the surface of nanotubes remained essentially unchanged over the entire temperature range investigated. This clearly demonstrates that the layer of surface-bound APTMS molecules is stable up to $250{ }^{\circ} \mathrm{C}$.

\subsection{XRD observations of nanotubes before and after heating}

Fig. 4 shows the diffraction patterns of the unmodified titanate nanotubes (sample TiNT-H) and the APTMS-grafted sample TiNT-NH ${ }_{2}-180$. The diffraction pattern of TiNT$\mathrm{H}$ can be assigned to the monoclinic crystal structure of $\left(\mathrm{H}_{2} \mathrm{Ti}_{3} \mathrm{O}_{7}\right)$ with lattice parameters: $a=16.03 \AA, b=3.75 \AA, c=9.19 \AA, \beta=101,45^{\circ}$. Comparing the diffractograms shown in Fig. 4 it is evident that the diffraction patterns of the samples TiNT-H and TiNT-NH ${ }_{2}-180$ are essentially identical. This further confirms that the grafting of APTMS molecules on the surface of TiNT-H does not influence the crystal structure of titanate nanotubes, as was observed by Raman spectroscopy as well.

Diffraction patterns of TiNT- $\mathrm{NH}_{2}-20,45,90$ and 180 after annealing at $500{ }^{\circ} \mathrm{C}$ and cooling to RT are shown in Fig. 5. After heating, the phase transition of surface modified nanotubes to anatase and partially to rutile phase was observed for all TiNT- $\mathrm{NH}_{2}-x$. The lines were assigned by comparison of the measured line intensities with the line intensities of $\mathrm{TiO}_{2}$ - anatase (JCPDS 084-1286) and $\mathrm{TiO}_{2}$ - rutile (JCPDS 88-1173). In addition to the expected lines of anatase and rutile, lines for several forms of sodium titanate appeared as 
well, specifically NT6 - $\mathrm{Na}_{2} \mathrm{Ti}_{6} \mathrm{O}_{13}$ (JCPDS 014-0277), NT3 - $\mathrm{Na}_{2} \mathrm{O}_{7} \mathrm{Ti}_{3}$ (JCPDS 0110290), $\mathrm{NO}-\mathrm{Na}_{0.80} \mathrm{O}_{6.40} \mathrm{Ti}_{3}$ and $\mathrm{NO} 2-\mathrm{Na}_{0.23} \mathrm{O}_{2} \mathrm{Ti}-$ (JCPDS 080-0018, 047-0562). Comparing the diffraction patterns of all the samples, it is apparent that the intensities of the most intense lines are slowly decreasing with increasing synthesis time, proven by the smallest intensity and the broadest lines of the pattern of TINT- $\mathrm{NH}_{2}-180$.

X-ray diffraction results are consistent with the Raman spectroscopy results. However in XRD patterns more detailed information of the phases different from pure $\mathrm{TiO}_{2}$ anatase was obtained. The appearance of sodium titanate phases after heating at temperature of $500{ }^{\circ} \mathrm{C}$ indicate that starting samples of titanate nanotubes contained some sodium between the titanate layers, probably due to an incomplete ion-exchange process. As a result, the sample has partially transformed to sodium titanate phases instead to anatase phase.

\subsection{The changes of titanate nanotubes during the modification process and after heat treatment observed by TEM methods}

The functionalized nanotubes TiNT- $\mathrm{NH}_{2}-20,45,90$ and 180 were characterized with TEM and HRTEM technique and selected area electron diffraction (SAED) before and after annealing (Figs. 6 and 7). Before annealing average inner and outer diameters were $(3.36 \pm 0.03) \mathrm{nm}$ and $(9.79 \pm 0.06) \mathrm{nm}$ respectively, as can be seen from size distributions shown in Figs. 8 (a) and (b). The distribution is fitted to log-normal graph while the sizes were measured from many TEM images of functionalised nanotubes. Since the inner and outer diameters were similar for all the samples, the measured data for all the functionalizations were treated as one sample for the statistical analysis. The typical 
appearance of TiNT- $\mathrm{NH}_{2}-x$ are shown in Figures 6 (a) to 6 (d). The lengths of the nanotubes varied from $300 \mathrm{~nm}$ to a few $\mu \mathrm{m}$ and were not changed after annealing. After thermal treatment to $500^{\circ} \mathrm{C}$ the outer diameter of titanate nanotubes decreased to $(8.16 \pm$ $0.05) \mathrm{nm}$, but the inner diameter remained the same, $(3.34 \pm 0.08) \mathrm{nm}$ in average (Figs. 7, 8 (c) - (d)) That is due to the phase transition to anatase $\mathrm{TiO}_{2}$ during heating where the hydrogen ions between the layers were removed. Two different morphologies were observed before and after heat treatment (Figs. 6 and 7); region with nanotubes and region with bundles. After thermal treatment nanotubes transform into $\mathrm{TiO}_{2}$ anatase nanotubes that are clearly evidenced by SAED of the region with nanotubes (Fig. 7 (e)). Although the phase transformation to anatase structure was expected after the heating of the hydrogen titanate nanotube, the conservation of tubular morphology after heating was not expected. Previous studies have shown that the hydrogen titanate nanotubes lose their tubular morphology and transform to nanowires or nanobelts after annealing at temperatures higher than $300{ }^{\circ} \mathrm{C}[14,29-32]$. Thus, to the best of our knowledge, this is the first time that the nanotubes of anatase $\mathrm{TiO}_{2}$ were synthesized by heating of the hydrogen titanate nanotubes prepared by the hydrothermal treatment. The phase transition to anatase $\mathrm{TiO}_{2}$ was also observed and confirmed by Raman spectroscopy and XRD diffraction for all investigated samples. Therefore, by functionalization of TiNT-H with the APTMS we have found new way of synthesis of anatase $\mathrm{TiO}_{2}$ nanotubes. In the SAED of the bundles area, sodium titanate phase were also observed besides the anatase $\mathrm{TiO}_{2}$ phase. The titanate phase, also observed by Raman spectroscopy and XRD, is remnant from synthesis of protonated form of nanotubes. The observation clearly indicates that ion - exchange of sodium ions with 
hydrogen ions has not been complete. However, this was the case only for long bundles. For the observed shorter nanotubes the ion-exchange was successful, and the modification with APTMS was completed as well.

\subsection{TEM and STEM observation of nanocomposites}

Three polymer composites with different amount of functionalised nanotubes; 0.19 , 0.38 and $1.52 \mathrm{wt} \%$, were studied by TEM and HRTEM (Fig. 9). In all three samples small aggregates of the tubes and the bundles were observed, as shown in Figs. 9 (a), (b) and (c), but rare larger aggregates were also found. Tubes and bundles preserved their morphology in all the aggregates, equivalent to that observed in APTMS modified TiNTs before heat treatment. The sample with the largest amount of TiNT $(1.52 \mathrm{wt} \%)$ contained many more small aggregates than the samples with 0.19 and $0.38 \mathrm{wt} \%$ of nanotubes. In all observed samples the small aggregates were of few hundred nanometers in size. The attachment of the TiNT to the epoxy matrix was studied by HRTEM (Figs. 9 (d), (e) and (f)). As was expected because of the formation of covalent bonds, all the nanotubes and bundles are completely inbuilt in the amorphous epoxy matrix. The lattice fringes of the nanotubes were hardly visible, which is due to the amorphous environment that suppresses the observation of the crystal lattice.

To study the distribution of the TiNTs within the epoxy matrix, large areas of thin slices of the polymer nanocoposites were observed by SEM working in STEM mode. Small aggregates, observed by TEM, were not intended to be observed by STEM, therefore only smaller magnifications were used. Although TEM measurements indicated mostly homogenously distributed small aggregates of nanotubes and bundles within epoxy matrix, 
the STEM measurements clearly indicated more inhomogeneous distribution of the TiNTs. Large aggregates of few micrometers in size were seldom observed in the sample containing smaller amount of nanotubes $(0.19 \mathrm{wt} \%)$. The overview image of such a typical large agglomerate is shown in Fig. 10 (a). Considerably more of the large aggregates were observed in sample with $1.52 \%$ of nanotubes. Moreover, in this sample the distribution of the nanotubes in circular shape, observed in some aggregates (Fig. 10 (b)) indicates the formation of bubbles during the sample synthesis. Bubbles of air enter the viscous epoxy resin during compounding and homogenization, and are naturally released from the mixture during the initial curing in the mould at RT. No persistent bubbles were found within the observed area of the samples (approximately $3 \mathrm{~mm}^{2}$ ).

\subsection{Dynamic mechanical properties of TiNT/epoxy nanocomposite}

Dynamic mechanical analysis (DMA) measures complex elastic modulus of polymer materials. The complex elastic modulus consists of the storage modulus, $E^{\prime}$, that represents the elastic behaviour, and the loss modulus, $E^{\prime \prime}$, that designates the viscous behaviour. The loss tangent is defined by $\tan \delta=E^{\prime \prime} / E^{\prime}$, and reaches the maximum in the transition region between the glassy state in which movement of polymer segments is frozen and the rubbery (viscoelastic) state in which the segments move freely. Therefore, the value of $\tan \delta$ is related to glass transition of polymers, but also to energy loss, internal friction and damping. Incorporation of fillers leads to changes in the thermo-mechanical spectrum that can give information about the adhesion between the constituents [33]. In the interphase, which forms between the filler and the polymer matrix, mobility of the polymer is hindered due to presence of filler, so a higher temperature is needed for polymer 
segments to move. In case of nanofillers, the interphase is significantly larger due to their larger surface area, so even a small addition of nanofiller (in our case $0.19 \mathrm{wt} \%$ of the final material) is expected to have noticeable influence on thermomechanical properties.

Fig. 11 shows $\tan \delta$ and $E^{\prime}$ of both the neat epoxy and the nanocomposites. The tan $\delta$ peak, attributed to the glass transition, shifts to higher temperatures (Fig. 11 (a)). If glass transition temperature, $T_{\mathrm{g}}$, is defined as the peak maximum, it shifts by almost $9{ }^{\circ} \mathrm{C}$ for the lowest nanofiller content (0.19 wt \%) (Table 4). Nanocomposites with larger nanofiller content show smaller but still significant shift of $T_{\mathrm{g}}$ to higher temperatures. This large influence of relatively small content of nanofiller is an indication of very good interaction between filler and matrix. This is probably due to formation of covalent bonds through reaction of amine groups bonded to TiNTs and the epoxy groups of the resin, which was also confirmed by HRTEM (Fig. 9). The fact that the smallest nanofiller content has the most significant influence on nanocomposite properties is a known phenomenon, directly linked to formation of large agglomerates. Since higher nanofiller content leads to larger and more numerous agglomerates, the interphase between the filler and the matrix is reduced, and so is its influence on the properties of nanocomposites [34].

Width at half height of the $\tan \delta$ relaxation peak of nanocomposites is considerably reduced in comparison with the neat epoxy resin. This is characteristic of greater homogeneity of the material, so the nanocomposites appear to have more regular structure than the neat epoxy polymer. We presume that the curing is affected by the presence of TiNT-NH -20 , which may act as catalysts or "nuclei" for the growth of epoxy network. On the other hand, increase in the height of the relaxation peaks of nanocomposites compared 
to that of neat epoxy can be linked to larger distance between crosslinks in the epoxy network [35], so this behaviour deserves further detailed study.

The shift of the glass transition to higher temperatures is also visible from $E^{\prime}$ curves (Fig. 11 (b)). The effectiveness of filler on the moduli of the composites can be represented by a coefficient $C$ such that [36]:

$$
C=\frac{\left(\frac{E_{q}^{t}}{E_{r}^{t}}\right) \operatorname{comp}}{\left(\frac{E_{q}^{t}}{E_{w}^{t}}\right) \text { resin }}
$$

where $E_{\mathrm{g}}^{\prime}$ and $E_{\mathrm{r}}^{\prime}$ are the values of the storage modulus in the glassy and rubbery region, respectively. Therefore, $C$ is the ratio of the storage modulus drop of the composite to that of the resin during the glass transition. The lower the value of $C$, the higher is the effectiveness of the filler. The measured $E^{\prime}$ values at 25 and $110^{\circ} \mathrm{C}$ were employed as $E_{\mathrm{g}}^{\prime}$ and $E_{\mathrm{r}}^{\prime}$ respectively, and the calculated coefficients are given in Table 4. Small coefficients prove the large effect of the filler. Table 4 shows that the lower the concentration of the nanofiller, the higher is its effectiveness. This is in agreement with the micrographs showing the agglomeration of nanofillers when added in higher concentrations. In the glassy state the modulus is determined primarily by the strength of the intermolecular forces and the way the polymer chains are packed. Although improvements of mechanical properties for the system nano- $\mathrm{TiO}_{2} /$ polymer have been reported [15-17, 20, 37], in this case there is no evidence of increase in elastic modulus below $T_{\mathrm{g}}$. In the glassy state (at 25 ${ }^{\circ} \mathrm{C}$ ), moduli do not significantly differ from each other, with an exception of the modulus of the nanocomposite with $0.19 \mathrm{wt} \%$ of the nanofiller which decreases about $20 \%$ (Table 4 ). However, in the rubbery state (at $115{ }^{\circ} \mathrm{C}$ ) there is an increase in modulus for 
nanocomposites with $0.38,0.76$ and 1.52 wt $\%$ of TiNTs, while the modulus for nanocomposite with $0.19 \mathrm{wt} \%$ of TiNTs remains the same as in the case of the neat epoxy. The increase in modulus in the rubbery state can be explained by nanoparticles acting as crosslinks between polymer chains [35]. The steady increase in the rubbery state modulus with temperature is due to additional curing at temperatures above that of the final cure, $120{ }^{\circ} \mathrm{C}$

\section{CONCLUSIONS}

In this work we studied temperature stability of surface modified protonated form of titanate nanotubes with the aim to find appropriate materials that could be further processed as nanofiller in preparation of nanocomposites. By in situ Raman spectroscopy at high temperatures we determined that the APTMS-grafted titanate nanotubes are stable in the temperature range between 200 and $400{ }^{\circ} \mathrm{C}$. The most stable sample was that with the shortest time of functionalization (20 minutes), TiNT- $\mathrm{NH}_{2}-20$. After cooling to RT besides the Raman bands of anatase and rutile form of $\mathrm{TiO}_{2}$, we observed the bands which could be assigned to sodium titanate form of nanotubes that was present only in the case of bundles morphology as was recognised by SAED.

In the case of separated nanotubes, only anatase $\mathrm{TiO}_{2}$ phase was observed after heating, as depicted by SAED, while HRTEM measurements have indicated that titanate nanotubes preserved their tubular morphology during the phase transition to the anatase form. To the best of our knowledge, this is the first time that hydrothermally formed titanate nanotubes preserved their tubular morphology after transformation to $\mathrm{TiO}_{2}$ during 
annealing. Tubular morphology can be of significant importance for better performance of titanate nanotubes during further processing.

Amine groups on the TiNTs surface can react with epoxy group to form covalent bonds between the matrix and the nanofiller. Therefore, the applicability of silanized titanate nanotubes (TiNT- $\mathrm{NH}_{2}$ ) as nanofiller for preparation of epoxy-based nanocomposites was studied in detail. It was shown that the silanized titanate nanotubes bond well with the epoxy matrix, although they form smaller and larger aggregates. We observed that very small addition $(0.19-1.52 \mathrm{wt} \%)$ of the nanofiller significantly increased the glass transition temperature and the modulus in rubbery state, thereby smaller amount of added nanofiller provide larger increase and better properties. Therefore we conclude that (3-aminopropyl)trimethoxy silane-grafted titanate nanotubes are promising nanofiller for preparation of epoxy-based nanocomposites.

\section{ACKNOWLEDGMENTS}

This work was financed by the Ministry of Science, Education and Sports of the Republic of Croatia (project no. 098-0982904-2898, 098-0982904-2927, 119-0000000-1158, 1251252970-3005), and Croatian-Germany bilateral project funded by the Ministry of Science, Education and Sports of the Republic of Croatia and DAAD agency in Germany. The DMA study was performed with financial support of the Croatian Science Foundation's Installation Grant. 


\section{REFERENCES:}

[1] Ou H H and LO L S 2007 Sep. Purif. Technol. 58 179-91

[2] Yuan Y Z and Su L S 2004 Colloids Surf. A. 241 173-83

[3] Kasuga T, Hiramatsu M, Hoson A, Sekino T and Niihara K 1998 Langmuir 14 3160-3

[4] Bavykin V D, Parmon N V, Lapkin A A and Walsh C F 2004 J. Mater. Chem. 14 $3370-7$

[5] Ma R, Bando Y and Sasaki T 2004 J. Phys. Chem. B 108 2115-9

[6] Zhang S, Peng M L, Chen Q, Du H G, Dawson G and Zhou Z W 2003 Phys. Rev. Lett. $91(25) 256103-4$

[7] Chen Q, Du H G, Zhang S and Peng M L 2002 Acta Cryst. B 58 587-93

[8] Bavykin V D, Walsh C F, Titanate and Titania Nanotubes Synthesis, Properties and Applications 2009 RSC Nanoscience \& Nanotechnology Cambridge 100-1

[9] Bavykin V D, Lapkin A A, Plucinski K P, Friedrich M J and Walsh C F 2005 J. Phys. Chem. B 109 19422-7

[10] Bavykin V D and Walsh C F 2007 J. Phys. Chem. C 111 14644-51

[11] Plodinec M, Friščić I, Iveković D, Tomašić N, Su S D and Zhang J 2010 J. Alloy. Compd. 499(1) 113-20

[12] Yoshida R and Suzuki Y 2005 Mater. Chem. Phys. 91 409-16

[13] Morgado Jr E, Abreu S A M, Moure T G, Marinkovic A B, Jardim M P and S A Araujo 2007 Mater. Res. Bull. 42 1748-61

[14] Gajović A, Friščić I, Plodinec M and Iveković D 2009 J. Mol. Struct. 924-926 183-91

[15] Brnardić I, Huskić M, Umek P, Fina A and Grgurić H T 2013 Phys. Status Solidi A $2102284-91$ 
[16] Patra N, Salerno M, Cozzoli P D, Barone A C, Ceseracciu L, Pignatelli F, Carzino R, Marini L and Athanassiou A 2012 Composites B 43 3314-9

[17] Cheng L Q, Pavlinek V, He Y, Li Z C, Lengalova A and Saha P 2007 Eur. Polym. J. $433780-6$

[18] Byrne T M, McCarthy E J, Bent M, Blake R, Gun'ko K Y, Horvath E, Konya Z, Kukovecz A, Kiricsi T and Coleman N J 2007 J. Mater. Chem. 17 2351-8

[19] Li Q, Zhang H, Tu Z, Yu J, Xiong C and Pan M 2012 J. Membrane Sci. 423-424 $284-92$

[20] Kralova D, Slouf M, Klementova M, Kuzel R and Kelnar I 2010 Mat. Chem. Phys. $124652-7$

[21] Iveković D, Gajović A, Čeh M and Pihlar B 2010 Electroanalysis 22 2202-10

[22] Taylor I and Howard G A 1993 Anal. Chim. Acta 271 77-82

[23] Bistričić L, Volovšek V, Danačić V and Šapić M I 2006 Spectrochim. Acta Part A 64 $327-37$

[24] Matinlinna P J, Areva S, Lassila J V L and Vallittu K P 2004 Surf. Interface Anal. 36 $1314-22$

[25] Bistricic L, Volovsek V and Dananic V 2007 J. Mol. Struct. 834-836 355-63

[26] Volovšek V, Bistričić L, Dananić and Šapić M I 2007 J. Mol. Struct. 834-836 414-8

[27] Boerio J F, Reflection-Absorption Infrared Spectra of $\gamma$-Aminopropyltriethoxysilane Adsorbed on Bulk Iron, in: Applications of polymer spectroscopy 1978 Academic Press Inc. (1978) New York, 171-2

[28] Liu H, Yang D, Zheng Z, Ke X, Waclawik E, Zhu H and Frost L R 2010 J. Raman Spect. 41 1331-7 
[29] Sun X and Li Y 2003 Chem. Eur. J. 9 2229-38

[30] Tsai C C and Teng H 2004 Chem. Mater. 16 4352-8

[31] Sreekantan S and Wei L C 2010 J. Alloys Compd. 490 436-442

[32] Kiatkittipong K, Scott J and Amal R 2011 ACS Appl. Mater. Interfaces 3(10) 3988-96

[33] Orefice L R, Hench L L and Brennan B A 2001 J. Braz. Soc. Mech. Sci. 23 1-8

[34] Tjong S C 2006 Mater. Sci. Eng. R 53 73-197

[35] De Nograro F F, Llano-Ponte R and Mondragon I 1996 Polymer 37 1589-600

[36] Pothan L A, Oommen Z and Sabu T 2003 Compos. Sci. and Technol. 63 283-293

[37] Carbelleira P and Haupert F 2010 Polym. Compos. 31 1241-6 
Table 1. Dimensions of samples for dynamical mechanical analysis

\begin{tabular}{ll}
\hline Filler content & Sample dimensions: length $\mathbf{x}$ width $\mathbf{x}$ height \\
\hline $0 \mathrm{wt} \%(0 \mathrm{phr})$ & $15 \mathrm{~mm} \times 2.6 \mathrm{~mm} \times 2.4 \mathrm{~mm}$ \\
$0.19 \mathrm{wt} \%(0.25 \mathrm{phr})$ & $15 \mathrm{~mm} \times 2.8 \mathrm{~mm} \times 2.5 \mathrm{~mm}$ \\
$0.38 \mathrm{wt} \%(0.5 \mathrm{phr})$ & $15 \mathrm{~mm} \times 3.0 \mathrm{~mm} \times 2.3 \mathrm{~mm}$ \\
$0.76 \mathrm{wt} \%(1 \mathrm{phr})$ & $15 \mathrm{~mm} \times 2.9 \mathrm{~mm} \times 2.3 \mathrm{~mm}$ \\
$1.52 \mathrm{wt} \%(2 \mathrm{phr})$ & $15 \mathrm{~mm} \times 2.6 \mathrm{~mm} \times 2.5 \mathrm{~mm}$ \\
\hline
\end{tabular}


Table 2. Influence of the silanization time on the quantity $\left(Q_{t}\right)$ of APTMS grafted on TiNT$\mathrm{H}(N=3$, number of measurements obtained for every sample).

\begin{tabular}{|c|c|c|}
\hline Sample & $t / \min$ & $Q_{t} / \mathrm{mmol} \mathrm{g}^{-1}$ \\
\hline TiNT-NH ${ }_{2}-20$ & 20 & $0.606 \pm 0.006$ \\
\hline TiNT-NH ${ }_{2}-45$ & 45 & $0.681 \pm 0.011$ \\
\hline TiNT-NH ${ }_{2}-90$ & 90 & $0.782 \pm 0.009$ \\
\hline TiNT-NH ${ }_{2}-180$ & 180 & $0.829 \pm 0.008$ \\
\hline
\end{tabular}


Table 3. Assignations of characteristic bands in vibrational (Raman and FT - IR) spectra of APTMS-modified TiNT. Assignation of Raman bands after refs. [14] and [23], and FT - IR bands after refs. [23], [24], [25], [26].

\begin{tabular}{ll}
\hline Band position $/ \mathbf{c m}^{-\mathbf{1}}$ & Band assignation \\
\hline $\begin{array}{l}\text { Raman: } \\
1000\end{array}$ & $\begin{array}{l}\text { trititanate lattice vibrations } \\
\mathrm{CH}_{2} \text { bending modes (aminopropyl segment, } \\
\text { multiple bands) }\end{array}$ \\
$1250-1450$ & $\mathrm{NH}_{2}$ asym. bending \\
1603 & $\mathrm{C}-\mathrm{H}$ stretching (aminopropyl segment) \\
$2897(\mathrm{sh})$ & \\
$2960(\mathrm{sh})$ & \\
& \\
\hline FTIR: & $\mathrm{SiO}$ stretching \\
900 & $\mathrm{Si}-\mathrm{O}-\mathrm{Ti}$ stretching \\
$942(\mathrm{sh})$ & $\mathrm{Si}-\mathrm{O}-\mathrm{Si}$ stretching (short linear chains) \\
1032 & $\mathrm{Si}-\mathrm{O}-\mathrm{Si}$ stretching (polysiloxane network) \\
1120 & $\mathrm{Si}-\mathrm{C}-\mathrm{H}$ sym. bending \\
1220 & $\mathrm{CH} \mathrm{H}_{2}$ bending modes (aminopropyl segment, \\
$1300-1450$ & multiple bands) \\
1510 & $\mathrm{NH}{ }_{3}^{+}$sym. bending \\
1623 & $\mathrm{H}-\mathrm{O}-\mathrm{H}$ bending \\
2923,2860 & $\mathrm{C}-\mathrm{H}$ stretching (aminopropyl segment) \\
$3700-2600$ & $\mathrm{O}-\mathrm{H}$ stretching (H ${ }_{2} \mathrm{O}$ and surface OH groups) \\
$($ broad) &
\end{tabular}


Table 4. The effectiveness of the TiNT filler on glass transition temperature, $T_{\mathrm{g}}$, and moduli of the composites, $E$, , represented by the coefficient $C$ calculated from storage moduli above and below $T_{\mathrm{g}}$.

\begin{tabular}{lccccc}
\hline Filler/wt\% & 0.19 & 0.38 & 0.76 & 1.52 & 0 \\
$\boldsymbol{T}_{\mathbf{g}}{ }^{\circ} \mathbf{C}$ & 95.6 & 93.5 & 92.0 & 91.0 & 86.9 \\
\hline $\boldsymbol{C}$ & 0.74 & 0.76 & 0.82 & 0.85 & - \\
$\boldsymbol{E}^{\prime} / \mathbf{G P a} @ 25{ }^{\circ} \mathbf{C}$ & 1.39 & 1.67 & 1.80 & 1.71 & 1.80 \\
$\boldsymbol{E}^{\prime} / \mathbf{M P a} @ 110{ }^{\circ} \mathbf{C}$ & 11.6 & 13.6 & 13.6 & 12.5 & 11.9
\end{tabular}




\section{FIGURE CAPTIONS:}

Figure 1: Vibrational spectra of titanate nanotubes before (TiNT-H) and after modification with APTMS (TiNT-NH 2 -180): (a) Raman spectra and (b) FT-IR spectra.

Figure 2: In situ high temperature Raman spectrum of surface modified nanotubes; lattice vibration region $50-1200 \mathrm{~cm}^{-1}$, (a) TiNT- $\mathrm{NH}_{2}-20$, (b) TiNT- $\mathrm{NH}_{2}-45$, (c) TiNT- $\mathrm{NH}_{2}-90$, (d) TiNT- $\mathrm{NH}_{2}-180$. T3 - bands of TiNT-H, A - anatase bands, $\mathrm{N}$ - sodium trititanate.

Figure 3: FT-IR spectra recorded during the heating of the sample TiNT- $\mathrm{NH}_{2}-180$ from room temperature to $250^{\circ} \mathrm{C}$. Spectra recorded at (from bottom to top) 25, 50, 100, $150,175,200$, and $250^{\circ} \mathrm{C}$ are shown.

Figure 4. XRD pattern at room temperature before annealing; hydrogen form of titanate nanotubes (TiNT-H), and after $3 \mathrm{~h}$ of modification with APTMS (TiNT- $\mathrm{NH}_{2}-$ $180)$.

Figure 5. XRD patterns of surface modified nanotubes after annealing at 500 : (a) TiNT$\mathrm{NH}_{2}-20$, (b) TiNT- $\mathrm{NH}_{2}-45$, (c) TiNT- $\mathrm{NH}_{2}-90$, (b) TiNT- $\mathrm{NH}_{2}-180$; R - rutil, A - anatase, NT6 - $\mathrm{Na}_{2} \mathrm{Ti}_{6} \mathrm{O}_{13}, \mathrm{NT} 3-\mathrm{Na}_{2} \mathrm{O}_{7} \mathrm{Ti}_{3}, \mathrm{NO}-\mathrm{Na}_{0.80} \mathrm{O}_{6.4} \mathrm{OTi}_{3}, \mathrm{NO} 2$ $\mathrm{Na}_{0.23} \mathrm{O}_{2} \mathrm{Ti}$.

Figure 6. TEM images of surface modified $\mathrm{H}$-form nanotubes before annealing: (a) and (b) TiNT $-\mathrm{NH}_{2}-20$, (c) and (d) TiNT $-\mathrm{NH}_{2}-180$

Figure 7. TEM images and SAED pattern of surface modified $\mathrm{H}$-form nanotubes after annealing: (a) and (b) TiNT- $\mathrm{NH}_{2}-20$, (c) and (d) TiNT- $\mathrm{NH}_{2}-180$, (e) SAED pattern of nanotubes of TiNT- $\mathrm{NH}_{2}-20$, (f) SAED pattern of bundles of TiNT$\mathrm{NH}_{2}-20$.

Figure 8. Size distributions of the average diameters of functionalised nanotubes: (a) inner and (b) outer diameters before heat treatment, (c) inner and (d) outer diameters after heat treatment. $\mathbf{d}$-average diameter determined by fitting to the log-normal distributions, $\mathrm{R}^{2}$ - goodness of the fit.

Figure 9. TEM images of polymer nanocomposites with different amount of functionalised nanotubes, TiNT- $\mathrm{NH}_{2}-20$ : (a) $0.19 \mathrm{wt} \%$, (b) $0.38 \mathrm{wt} \%$ and (c) $1.52 \mathrm{wt} \%$, and HRTEM of the nanocomposites: (d) $0.19 \mathrm{wt} \%$, (e) $0.38 \mathrm{wt} \%$ and (f) $1.52 \mathrm{wt} \%$. 
Figure 10. STEM images of polymer composites with different amount of functionalised nanotubes, TiNT- $\mathrm{NH}_{2}-20$ : (a) $0.19 \mathrm{wt} \%$ and (b) $1.52 \mathrm{wt} \%$.

Figure 11. The temperature scans of the loss tangents (a) and storage moduli (b) for neat epoxy polymer and for the TiNT/epoxy nanocomposites. 